\title{
Oxygen microprofile in the prepared sediments and its implication for the sediment oxygen consuming process in a heavily polluted river of China
}

\author{
Chao Wang ${ }^{1} \cdot$ Wanying Zhai $^{2} \cdot$ Baoqing Shan ${ }^{3}$
}

Received: 26 May 2015 / Accepted: 11 January 2016/Published online: 22 January 2016

(C) Springer-Verlag Berlin Heidelberg 2016

\begin{abstract}
Dissolved oxygen (DO) microprofiles of prepared sediments from 24 sampling sites in the Fuyang River were measured using a gold amalgam microelectrode in this study. The measured microprofiles can be divided into four types. In type I profiles, DO kept constant in the overlying water and decreased smoothly in the pore water; in type II profile, DO showed fluctuation in the pore water; in type III profiles, DO showed peak in the SWI; in type IV profiles, DO decreased obviously in the overlying water. Type I profiles indicated the absence of benthic organisms and thus the degradation of the sediment habitat. Type II and III profiles indicated the activity of benthic animal and epipelic algae, which is common in the healthy aquatic sediment. Type IV profiles indicated that the excessive accumulation of pollutants in the sediment and thus the serious sediment pollution. There are nine sites showing type I profile, three sites showing type II profile, nine sites showing type III profile, and three sites showing type IV profile in the Fuyang River. The dominance of type I and appearance of type IV indicated that sediment oxygen consumption processes in the Fuyang River were strongly influenced by the sediment pollutants release and the vanish of benthic organisms. The
\end{abstract}

Responsible editor: Philippe Garrigues

Chao Wang

cwrcees@163.com

1 Changjiang Water Resource Protection Institution, Wuhan 430051, China

2 Yangtze Valley Water Environment Monitoring Center, Wuhan 430010, China

3 State Key Laboratory on Environmental Aquatic Chemistry, Research Center for Eco-Environmental Sciences, Chinese Academy of Sciences, Beijing 100085, China pharmacy, metallurgy, and curriery industries may contribute to the sediment deterioration and thus to the occurrence of type I and type IV oxygen profiles in the Fuyang River.

Keywords DO $\cdot$ Microprofile $\cdot$ Fuyang river $\cdot$ Oxygen consumption

\section{Introduction}

Sediment is the primary zone of oxygen consumption in the river. The degradation of organic matter in the sediment, the oxidization of inorganic reduced material, and the respiration of benthic organisms can all result in sediment oxygen consumption (Wetzel 2001). Sediment oxygen consumption can reduce the oxygen content in the water column and influences the water quality heavily. Sediment oxygen demand contributes greatly to the total DO demand in aquatic systems ( $\mathrm{Di}$ Toro and Connolly 1980; Hanes and Irvine 1966). In some rivers, sediment oxygen demand has been shown to comprise over half of the total oxygen demand (Matlock et al. 2003). High sediment oxygen demand always results in hypoxia of the river water (Mehring et al. 2014). The degradation of organic matter coupled with sediment oxygen consumption can result in the release of nutrients and metals, such as ammonium, phosphorus, nitrogen, iron, and manganese into the water column (Gunnison et al. 1983), which can lead to severe water quality problems. Besides, the sediment oxygen consumption is closely related to the benthic habitat condition. The existence of benthic invertebrates may influence the sediment oxygen-consuming process (Ferguson et al. 2013), and the sediment oxygen content can also effect the distribution of these benthic community (Danise et al. 2013).

DO microprofiles are useful for investigation of the sediment oxygen consumption, and the distribution pattern of DO 
microprofile can reflect the DO consumption process. Generally, the movement of oxygen in sediments is attributed to vertical diffusion (Blackburn et al. 1994). However, some studies have clearly shown that photosynthesis of benthic microflora can contribute to the sediment-water interface (SWI) oxygen content (Revsbech and Jorgensen 1983). Irrigation (i.e., the pumping activity of tube-dwelling animals) can also significantly influence the transport of solutes in sediments (Aller 1980) and thus change the pattern of oxygen distribution. Moreover, reduced substances such as $\mathrm{NH}_{4}^{+}, \mathrm{Mn}^{2+}, \mathrm{CH}_{4}$, and $\mathrm{H}_{2} \mathrm{~S}$ in pore water can deplete oxygen in the sediment pore water (Sweerts et al. 1991; Van Cappellen and Wang 1996), which would result in variations in the DO microprofile.

The Fuyang River is one of the main systems of the Haihe River, which is heavily impacted by anthropogenic activities and threatened by serious water pollution ( $\mathrm{Li}$ et al. 2000). Sediment in this area has displayed various problems such as heavy metal toxicity (Liu et al. 2006) and nutrient release (Sun et al. 2009), which can influence the DO consumption process directly or indirectly and produce unique sediment
DO distribution. In this study, the sediment DO microprofiles of 24 sampling sites in the Fuyang River were measured. The objective of this study was to investigate the chemical and biological processes of DO consumption in a heavily polluted river through the oxygen microprofile in the prepared sediment.

\section{Materials and methods}

\section{Study area and sampling sites}

The Fuyang River $\left(36^{\circ} 23^{\prime}-38^{\circ} 14^{\prime} \mathrm{N}, 114^{\circ} 19^{\prime}-116^{\circ} 7^{\prime} \mathrm{E}\right)$ (Fig. 1) is a well-known tributary of the Haihe River in North China that is characterized by high population density and severe water pollution. The main channel of the Fuyang River is $402 \mathrm{~km}$, originating from the mountains in Handan and ending at its confluence with the Hutuo River in Hengshui. The New Fuyang River, which was constructed for the purpose of flood diversion, runs parallel to the downstream
Fig. 1 Fuyang River system and the sampling site location. The solid line in the inset is the boundary of the Haihe River basin, and the dashed frame represents the spatial extent of the research

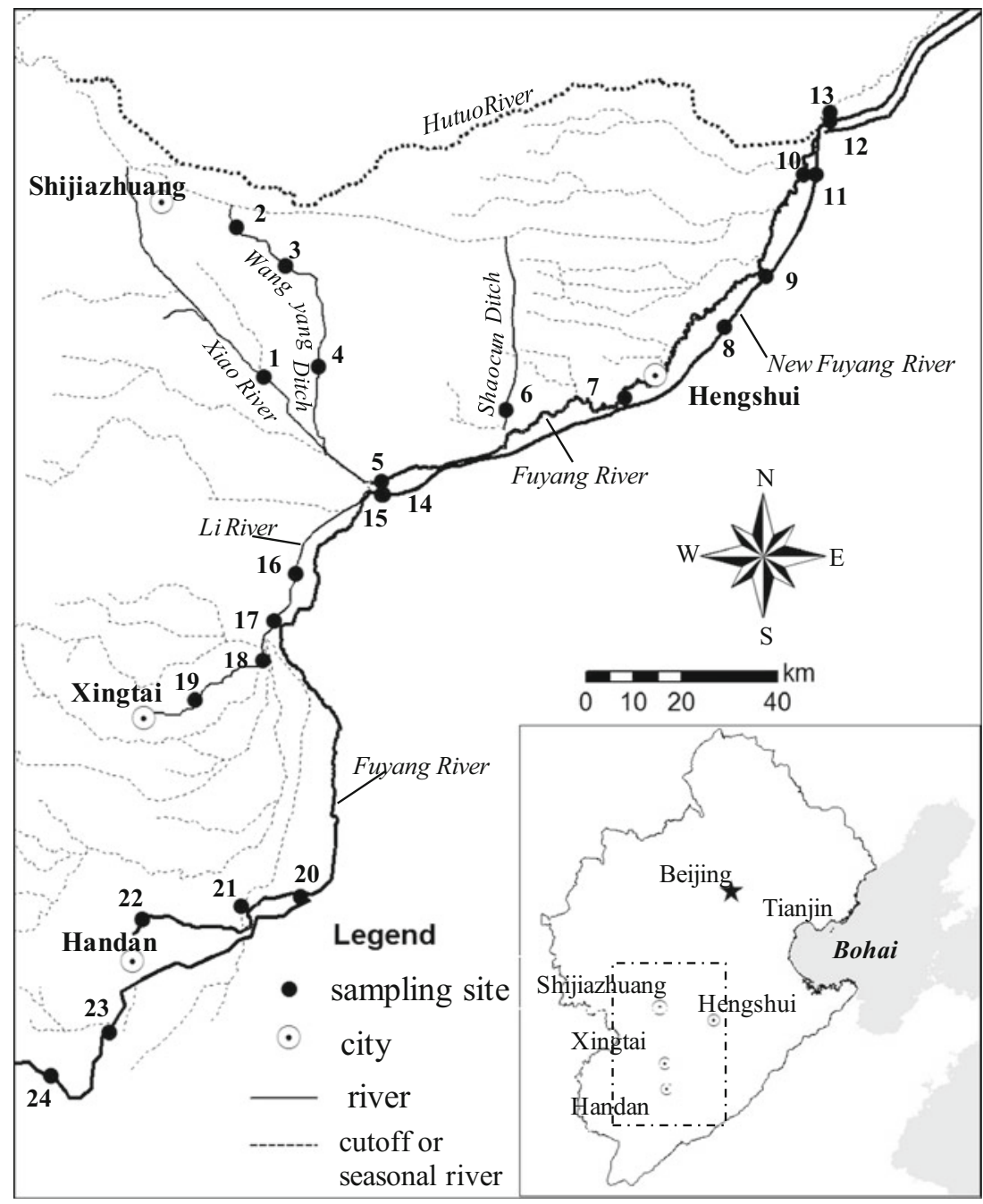


portion of the Fuyang River. Generally, the upstream of the mainstream (the headwater to the confluence of Xiao River) is called Handan Reach, and the downstream of the mainstream (the confluence of Xiao River to the confluence of Hutuo River, including the New Fuyang River) is called Hengshui Reach. Although there are many tributaries in the water system, most of them are permanent or seasonal cutout as a result of agricultural irrigation and large-scale urban water supply. The primary tributaries of the Fuyang River with flowing water include the Xiao River, Wangyang Ditch, Shaocun Ditch, and Li River.

Water pollution of the Fuyang River is the heaviest in the Haihe River system (WRPBHRB 2013). The tributaries and the mainstream receive domestic and industrial wastewater discharged by Handan, Xingtai, Hengshui, and Shijiazhuang in the Fuyang River Basin. Shijiazhuang, which is the provincial capital, as well as the largest city of Hebei province, has a population of 12.7 million and is the largest medicine production base of China. The Xiao River and Wangyang Ditch receive wastewater from Shijiazhuang. Xingtai has a population of 7.2 million, its primary industry is papermaking and metallurgy, and most of its wastewater is discharged into the Li River. Handan, which is the main pollution source of the Fuyang River upstream, has a population of 10.2 million and is famous for its iron and steel industry. Hengshui, which has a population of 4.4 million, discharges its wastewater into the mainstream of the Fuyang River. In 2012, a total of 0.52 billion tons of wastewater were discharged into the Fuyang River. According to Fig. 2, more than $60 \%$ of the industrial wastewater received by Handan Reach comes from metallurgy, papermaking contributes over $80 \%$ of the wastewater in the $\mathrm{Li}$ River, and almost all of the industrial wastewater in the Wangyang Ditch is discharged by pharmacy. The primary source of wastewater in the Xiao River is petrochemistry. In Shaocun Ditch, the wastewater mainly comes from tannery industry. While in Hengshui Reach, livestock is the

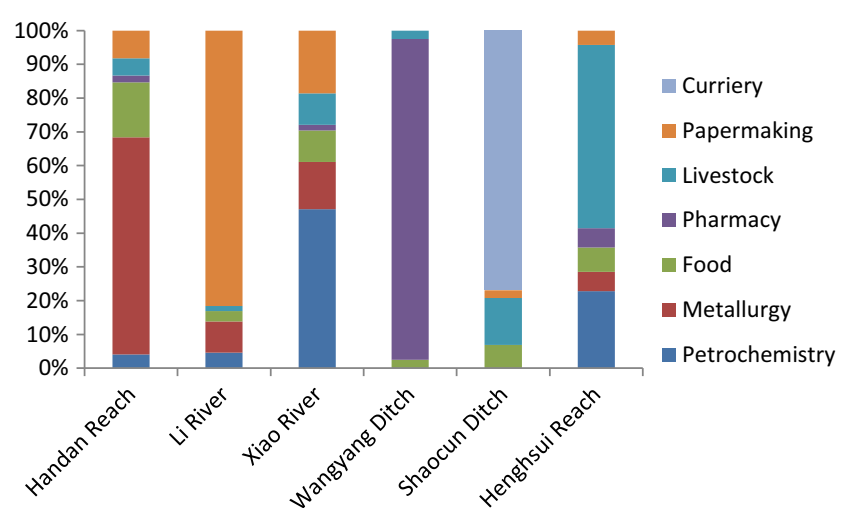

Fig. 2 Composition of the industrial effluent discharges in the Fuyang River. Data source: The Pollution Source Census 2010, PRC most important source of wastewater. Under the impact of long-term pollution discharge, the deterioration of water quality was obvious, with average ammonia concentrations as high as $10 \mathrm{mg} / \mathrm{L}$ and average COD levels as high as $86 \mathrm{mg} / \mathrm{L}$ (Wenzan et al. 2012).

A total of 24 sampling sites were set over the primary tributaries and mainstream, and all sites were numbered from one to 24. Site 1 is in Xiao River, sites 2, 3, and 4 are in Wangyang Ditch, site 6 is in Shaocun Ditch, sites 7 to 15 are in Hengshui Reach of the mainstream, sites 16 to 19 are in $\mathrm{Li}$ River, and sites 20 to 24 are in Handan Reach of the mainstream. The water quality at each sampling site was shown in Table 1. The DO content was lower than $2 \mathrm{mg} / \mathrm{L}$ in most sites, and the average value was $1.5 \mathrm{mg} / \mathrm{L}$. The average $\mathrm{NH}_{3}-\mathrm{N}$ content was as high as $19.5 \mathrm{mg} / \mathrm{L}$ (maximum $76.8 \mathrm{mg} / \mathrm{L}$, minimum $0.9 \mathrm{mg} / \mathrm{L}$ ), and the average TOC content was $76.7 \mathrm{mg} / \mathrm{L}$ (maximum $574.3 \mathrm{mg} / \mathrm{L}$, minimum $9.8 \mathrm{mg} / \mathrm{L}$ ). Overall, water pollution in this area was serious, and the water quality deterioration was obvious.

The surface mud used for sediment preparation was collected with a grab sampler. All of the samples were collected under the water. Surface mud collected from each site was stored at $4{ }^{\circ} \mathrm{C}$ until the experiment started. The physicochemical properties, including organic matter content and grain size were shown in Table 1 . The average organic matter content was $10.50 \%$ (maximum $29.13 \%$, minimum $3.78 \%$ ). The average grain size was 35.20 um (maximum 62.23 um, minimum $15.74 \mathrm{um})$.

\section{Method for sediment preparation}

Before the experiments, about $70 \mathrm{~g}$ of sediment were mixed with $200 \mathrm{ml}$ deionized water in a 400-ml beaker. Detritus and plant residues in the sediment were picked out to prevent damage to the microelectrode during determination of the DO microprofile. After 2 days of deposition in the dark at $25^{\circ} \mathrm{C}$, stable sediment with clear SWI was formed. This sediment was subsequently used for determination of the DO microprofile.

Sediment porosity $\varphi$ was measured according to Eq. (1) (Berner 1980) after the DO microprofile was completed:

$\varphi=\frac{V_{p w}}{V_{b}}$

where $V_{p w}$ is the volume of pore water and $V_{b}$ is the bulk volume of the sediment. To determine the volume of bulk sediment and overlying water, the SWI and the top of the overlying water were marked on a beaker. The beaker with sediment and water was then weighed and recorded as $M_{1}$, after which it was placed into a drying oven at $105{ }^{\circ} \mathrm{C}$ until the water dried, at which time the beaker with the dry sediment was weighed $\left(M_{2}\right)$. Finally, the 
Table 1 Characteristics of the sampling site water quality, collected surface mud and the prepared sediment

\begin{tabular}{|c|c|c|c|c|c|c|c|}
\hline \multirow[t]{2}{*}{ Sampling site } & \multicolumn{4}{|c|}{ Water quality } & \multicolumn{2}{|l|}{ Surface mud } & \multirow{2}{*}{$\begin{array}{l}\text { Prepared sediment } \\
\text { Porosity }\end{array}$} \\
\hline & $\mathrm{DO} \mathrm{mg} / \mathrm{L}^{\mathrm{a}}$ & $\mathrm{pH}^{\mathrm{a}}$ & $\mathrm{NH}_{3}-\mathrm{N} \mathrm{mg} / \mathrm{L}^{\mathrm{b}}$ & $\mathrm{TOC} \mathrm{mg} / \mathrm{L}^{\mathrm{c}}$ & Grain size $(d 50)^{\mathrm{d}}$ & Organic matter content $\mathrm{e}^{\mathrm{e}}$ & \\
\hline 1 & 3.3 & 8.2 & 33.0 & 113.3 & 38.82 & $9.61 \%$ & 0.85 \\
\hline 2 & 0.1 & 7.5 & 20.3 & 77.3 & 49.92 & $4.46 \%$ & 0.71 \\
\hline 3 & 0.1 & 7.6 & 20.6 & 87.7 & 43.33 & $3.78 \%$ & 0.67 \\
\hline 4 & 1.8 & 7.7 & 2.4 & 149.0 & 44.42 & $14.33 \%$ & 0.85 \\
\hline 5 & 2.5 & 7.7 & 7.4 & 76.9 & 24.71 & $24.76 \%$ & 0.92 \\
\hline 6 & 1.1 & 7.8 & 12.5 & 83.4 & 50.49 & $14.70 \%$ & 0.87 \\
\hline 7 & 0.1 & 7.7 & 76.8 & 574.3 & 62.24 & $9.35 \%$ & 0.90 \\
\hline 8 & 1.5 & 7.7 & 44.1 & 50.9 & 23.77 & $7.53 \%$ & 0.78 \\
\hline 9 & 0.9 & 7.5 & 16.1 & 39.8 & 32.96 & $5.31 \%$ & 0.73 \\
\hline 10 & 1.8 & 7.6 & 0.9 & 22.9 & 15.74 & $4.84 \%$ & 0.53 \\
\hline 11 & 0.6 & 7.6 & 16.1 & 31.1 & 22.35 & $6.31 \%$ & 0.57 \\
\hline 12 & 0.6 & 7.6 & 13.8 & 49.1 & 20.19 & $4.49 \%$ & 0.67 \\
\hline 13 & 0.6 & 7.6 & 32.9 & 35.8 & 39.24 & $5.24 \%$ & 0.67 \\
\hline 14 & 0.5 & 7.7 & 34.7 & 52.7 & 23.08 & $23.64 \%$ & 0.87 \\
\hline 15 & 5.0 & 8.5 & 20.9 & 50.7 & 39.35 & $29.13 \%$ & 0.86 \\
\hline 16 & 0.8 & 6.6 & 34.5 & 88.8 & 24.43 & $16.52 \%$ & 0.68 \\
\hline 17 & 1.4 & 2.4 & 24.7 & 119.1 & 25.63 & $8.85 \%$ & 0.80 \\
\hline 18 & 0.9 & 7.4 & 16.1 & 39.6 & 29.97 & $13.50 \%$ & 0.55 \\
\hline 19 & 4.0 & 8.2 & 4.7 & 22.9 & 39.11 & $6.88 \%$ & 0.51 \\
\hline 20 & 1.8 & 7.5 & 7.1 & 23.6 & 57.72 & $4.71 \%$ & 0.43 \\
\hline 21 & 0.6 & 7.3 & 2.6 & 11.1 & 17.90 & $6.23 \%$ & 0.87 \\
\hline 22 & 1.8 & 7.6 & 2.2 & 9.8 & 26.44 & $9.11 \%$ & 0.70 \\
\hline 23 & 1.6 & 7.5 & 17.0 & 17.5 & 49.16 & $6.86 \%$ & 0.64 \\
\hline 24 & 1.6 & 7.7 & 7.4 & 14.1 & 43.83 & $11.90 \%$ & 0.78 \\
\hline Average & 1.5 & 7.4 & 19.5 & 76.7 & 35.20 & $10.50 \%$ & 0.72 \\
\hline
\end{tabular}

${ }^{a}$ Measured using a handheld multiparameter instrument (YSI 556, Yellow Springs, OH, USA)

${ }^{\mathrm{b}}$ Measured using a SmartChem ${ }^{\circledR} 200$ discrete chemistry analyzer (Westco Scientific Instruments, Brookfield, CT, USA) following EPA method 350.1

${ }^{\mathrm{c}}$ Measured with a TOC analyzer (Shimadzu TOC-VCPH, Kyoto, Japan)

${ }^{\mathrm{d}}$ The maximum particle diameter below which $50 \%$ of the sample volume exists - also known as the median particle size by volume. measured by Malvern laser particle size analyzer

${ }^{\mathrm{e}}$ Measured by loss on ignition

${ }^{\mathrm{f}}$ See section 2.2

beaker was cleaned and filled with water to the marks, and the volumes required to reach the two marks were recorded as $V_{1}$ and $V_{2}$. The volume of pore water was then calculated using Eq. (2):

$V_{p w}=\frac{M_{p w}}{\rho_{w}}=\frac{\left(M_{1}-M_{2}-V_{2}^{*} \rho_{w}\right)}{\rho_{w}}$

where $M_{p w}$ is the mass of pore water and $\rho_{\mathrm{w}}$ is the density of water, which is 1 . Finally, the porosity was calculated by substituting Eq. (2) into Eq. (1) as follows:

$\varphi=\frac{\left(M_{1}-M_{2}-V_{2}\right)}{V_{1}}$.
The porosity of the deposited sediment was shown in Table 1 , and the average value was 0.72 (maximum 0.92 , minimum 0.43).

\section{Method for DO profile detection}

A gold amalgam microelectrode was used to measure the DO microprofiles in the sediment using the method developed by (Brendel and Luther 1995). Briefly, a glass tube with a 4-mm outer diameter and 3-mm inner diameter was heated in the middle, and the tip was pulled until the diameter was less than $0.4 \mathrm{~mm}$. Conductive silver epoxy was then used to connect a 5 -cm gold wire with a $100-\mu \mathrm{m}$ diameter to a $10-\mathrm{cm}$ silver wire with a 0.5 -mm diameter. Next, the gold wire was inserted into 
the tip of the glass capillary from the larger diameter and sealed with epoxy. When the epoxy was solidified, the end of the silver wire was used as the electrical contact of the electrode. The tip of the electrode was polished with a micropolisher (EG-44, Narishige, Japan) and washed in ultrasonic cleaner for $40 \mathrm{~s}$. After polishing was completed, the electrode was plated with $\mathrm{Hg}$. We conditioned the $\mathrm{Au} / \mathrm{Hg}$ amalgam interface through a $-9 \mathrm{~V}$ polarization for $90 \mathrm{~s}$ in $1 \mathrm{~N} \mathrm{NaOH}$ solution, after which, we calibrated for DO using the Winkler titration method, as described by (Brendel and Luther 1995). A CHI 660 electrochemical analyzer with a standard three-electrode system was used to measure the oxygen concentration. The Ag wire was then placed into a chloride solution and polarized for $20 \mathrm{~s}$ to make a solid $\mathrm{Ag} / \mathrm{AgCl}$ electrode (Luther III et al. 2008).

The Pt electrode and solid $\mathrm{Ag} / \mathrm{AgCl}$ electrode were placed in the overlaying water during measurement of the profile, and the $\mathrm{Hg}-\mathrm{Au}$ microelectrode moved to the sediment vertically under the control of a micromanipulator at a minimal step of $0.3 \mathrm{~mm}$. The sediment-water interface (SWI) was decided by a magnifying glass (Komada, Reimers et al. 1998). When the electrode was down to the sediment slowly, the tip of the electrode was observed through a magnifying glass. The position where the tip reached the sediment was set as the SWI. Square wave voltammetry (SWV) was selected as the scan method, and a single potential scan from -0.10 to $-1.75 \mathrm{~V}$ vs. $\mathrm{Ag} / \mathrm{AgCl}$ was used to measure the dissolved oxygen. The primary parameters in SWV were: scanning rate $25 \mathrm{~Hz}$, square wave amplitude $25 \mathrm{mV}$, and step increase $4 \mathrm{mV}$. For each measurement, a full potential range scan required $20 \mathrm{~s}$. To confirm the homogeneity of the prepared sediments, the first three sediments were chosen to measure profile duplicates. Three duplicate profiles in different area within one sediment were almost the same, which indicated that the prepared sediment was homogenous. Therefore, oxygen profiles were measured only once in the rest of sediments.

\section{Results}

The oxygen profiles in the prepared sediment varied in the overlying water, the SWI, and the sediment pore water (Fig. 3). In the overlying water, the oxygen concentration remained constant in most sediments. For example, the oxygen concentration in the overlying water remained as about $8.3 \mathrm{mg} / \mathrm{L}$ in sediment 6 and as about $5.3 \mathrm{mg} / \mathrm{L}$ in sediment 7 . According to Fig. 3, sediments 1, 2, 6, 7, 8, 9, 10, 12, 17, 19, $20,21,22,23$, and 24 all showed this kind of distribution pattern in the overlying water. However, there were several sediments showing declined oxygen concentration in the overlying water, which were represented by sediment 5 , sediment 16 , and sediment 18 . The oxygen concentration in the overlying water declined from about $7.8 \mathrm{mg} / \mathrm{L}$ to about $2 \mathrm{mg} /$
$\mathrm{L}$ in sediment 5 , from about 3.4 to $1 \mathrm{mg} / \mathrm{L}$ in sediment 16 , and from 7 to $1 \mathrm{mg} / \mathrm{L}$ in sediment 18 . Besides, there were also some sediments showing fluctuated oxygen concentration in the overlying water such as sediment 4 , sediment 11 , and sediment 15 . The oxygen concentration varied between about $6 \mathrm{mg} / \mathrm{L}$ to $7 \mathrm{mg} / \mathrm{L}$ in sediment 4 , about 5.8 to $6.2 \mathrm{mg} / \mathrm{L}$ in sediment 11 , and about 6.2 to $6.8 \mathrm{mg} / \mathrm{L}$ in sediment 15 .

In the SWI, the oxygen concentration presented a peak in some sediments such as $6,7,9,12,19$, and 22. For example, in sediment 1 , the oxygen concentration increased from about 5 to $6 \mathrm{mg} / \mathrm{L}$ within a small layer just above the SWI and declined quickly once below the SWI, which formed a peak of the oxygen concentration in the SWI. However, in sediments 2, 4, 5, 13,16 , and 21 , the oxygen concentration began to decline before the profile curve reached the SWI. For example, the oxygen concentration declined from about $6.5 \mathrm{mg} / \mathrm{L} 0.3 \mathrm{~mm}$ above the SWI to $5.5 \mathrm{mg} / \mathrm{L}$ in the SWI in sediment 4 . In sediments such as $3,8,20$, and 23 , the oxygen concentration in the overlying water remained constant until the profile curve reached the SWI and began to decline just below the SWI.

In the pore water, the oxygen concentration fluctuated in some sediments which was represented by sediment 11 . In sediment 11 , the oxygen concentration decreased from about 5.8 to $0.5 \mathrm{mg} / \mathrm{L}$ in $0-2-\mathrm{mm}$ depth and increased to about $1.3 \mathrm{mg} / \mathrm{L}$ in $3.5-\mathrm{mm}$ depth and then declined to $0 \mathrm{mg} / \mathrm{L}$ in $5-$ $\mathrm{mm}$ depth. However, most of the sediments showed smoothly decreasing oxygen profile in the pore water. Some of them declined sharply such as sediments $1,3,4$, and 7 , while some of them declined slowly, such as sediments 2,6 , and 10. For example, the oxygen concentration declined from $6 \mathrm{mg} / \mathrm{L}$ to almost $0 \mathrm{mg} / \mathrm{L}$ within about $1-\mathrm{mm}$ depth in sediment 1 and declined from 6 to $0 \mathrm{mg} / \mathrm{L}$ within 8-mm depth in sediment 10 .

\section{Discussions}

The oxygen penetration depth in sediment 10 , sediment 12 , and sediment 13 was greater than other sediment samples, which may be caused by the relative low organic matter content of the sediment. The organic matter content in these three sediments were $4.84,4.49$, and $5.24 \%$, which were lower than most of the other sediments. Besides these three sediments, the oxygen penetration in sediment 20 and sediment 23 was also large (below $4 \mathrm{~mm}$ ), and their organic content were only 4.71 and $6.86 \%$. Depth of oxygen penetration inside sediment indicates magnitude of sediment oxygen demand. In other words, a higher requirement of oxygen flux exerted by sediment decay reduces depth of oxygen penetration (Cai et al. 1996). The organic matter decomposition is the main driver for oxygen reactions in the sediment (Di Toro 1980). Generally, the lower the organic matter content in the sediment, the lower the oxygen consumption capacity will be (Cai et al. 2010). However, organic matter content was not the only 

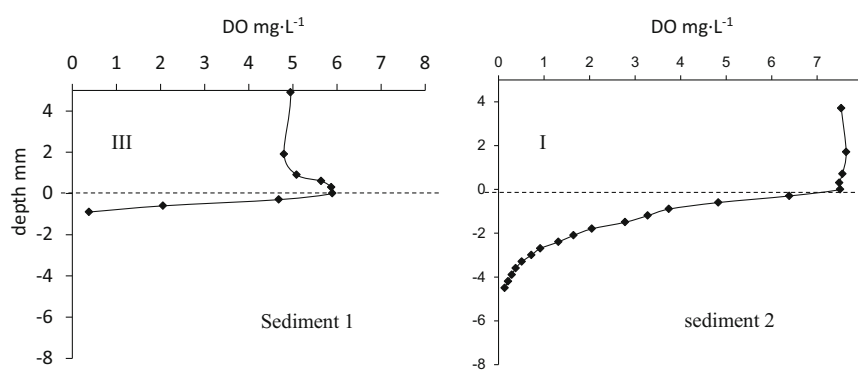

$\mathrm{DO} \mathrm{mg} \cdot \mathrm{L}^{-1}$

DO $\mathrm{mg} \cdot \mathrm{L}^{-1}$
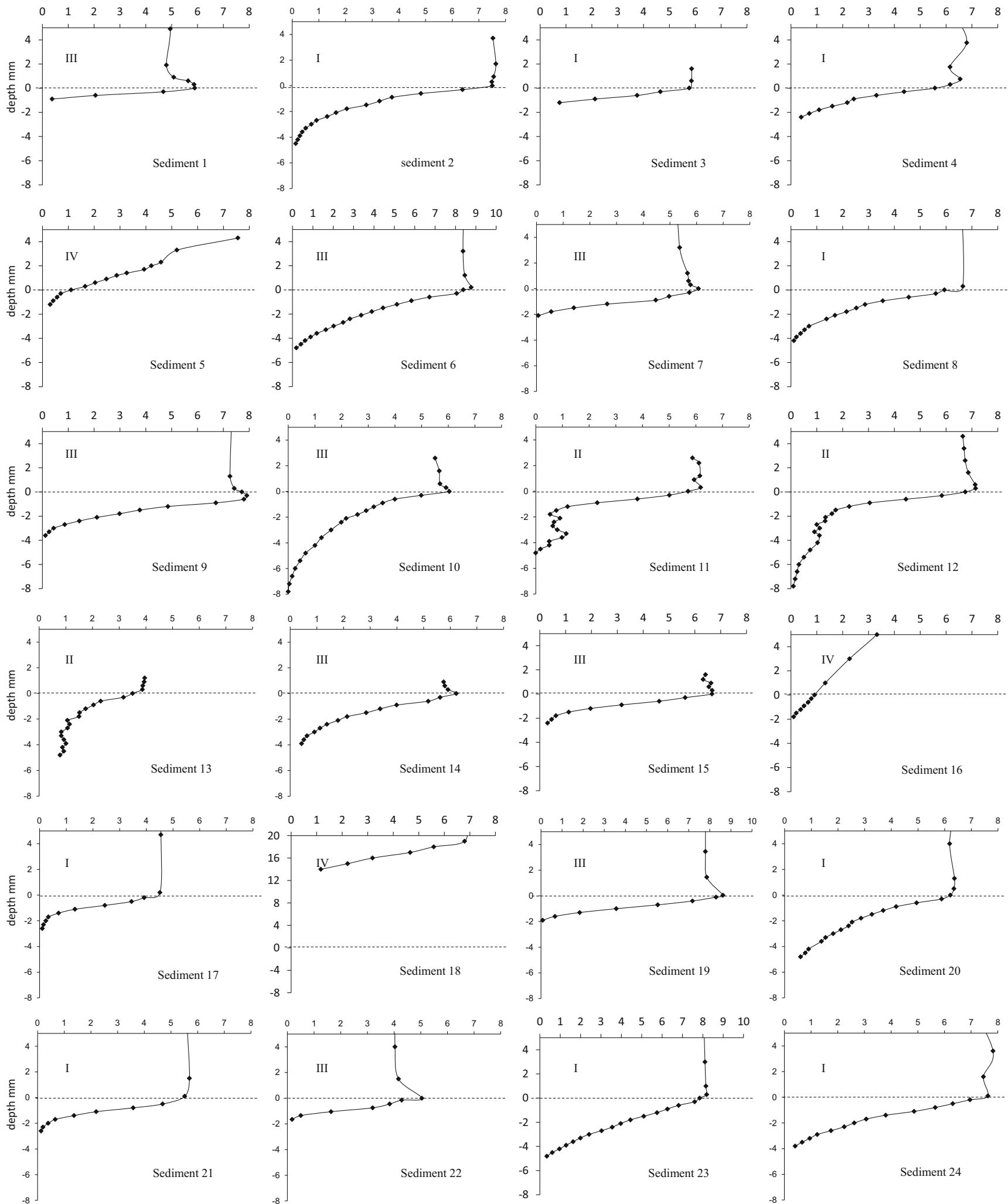

Fig. 3 Measured DO microprofiles in the prepared sediments. The dashed line is SWI and the Roman numerals represent the profile type discussed in section 4

factor, the penetration depth may be affected by other factors such the pollution source. For example, although the organic matter content in sediment 6 was as high as $14.70 \%$, its penetration depth was below $4 \mathrm{~mm}$. In this area, the tannery 
industry was dense. The tannery wastewater contains lots of heavy metal Cr (Wei-min 2009), which is toxic to the microorganisms and thus suppresses the oxygen-consuming capacity of the sediment. Besides, the organic matter was easy to break down in some sediments, while was refractory in other sediments. The variation of organic matter composition may also have contributed to the appearance of disproportionate relationship between organic matter and oxygen penetration.

The 24 profiles could be divided into four types (Fig. 4). In type I, which was represented by sediment 2 , the DO microprofile remained constant in the overlying water and decreased smoothly in the sediment. In type II, which was represented by sediment 11, the DO microprofile was not as smooth as in type I, and some variations were observed in the sediment. Type III DO microprofiles were characterized by an obvious peak in the SWI as represented by sediment 1. In the type IV DO microprofiles (e.g., sediment 5), the DO concentration displayed a significant decrease in the overlying water and even was exhausted above the sediment.

The oxygen profiles reflected different oxygen consumption processes. The smooth decrease in DO concentration in sediment pore water in the type I profile likely resulted from the homogenous sediment and thus the uniformly distributed DO reaction rate. This is because both sediment heterogeneity (Pischedda et al. 2008) and DO reaction rate (Cai and Sayles 1996) are key factors influencing the distribution of DO in sediment. The DO fluctuation in the type II profile may be caused by the bioturbation of fauna existing in the sediment. In sediments, bioturbation (i.e., the diffusion-like transport caused by fauna activity) will influence the overall transport of DO (Aller 1980). Benthic organisms can construct complex structures in the sediment column and form sediment pores with various shapes and sizes that may or may not be permanent (Dufour et al. 2005). These structures may be actively ventilated by their inhabitants and thus possess higher DO levels (Aller and Aller 1998; Kristensen 1983). Epipelic algae is responsible for the increase in DO in the SWI of type III profiles. Photosynthesis by epipelic algae may make a significant contribution to the increase of oxygen in the SWI (Hargrave 1969). The same phenomenon was reported by (Revsbech and Jorgensen 1983) in a sediment DO microprofile developed using a microelectrode. The consumption of DO in

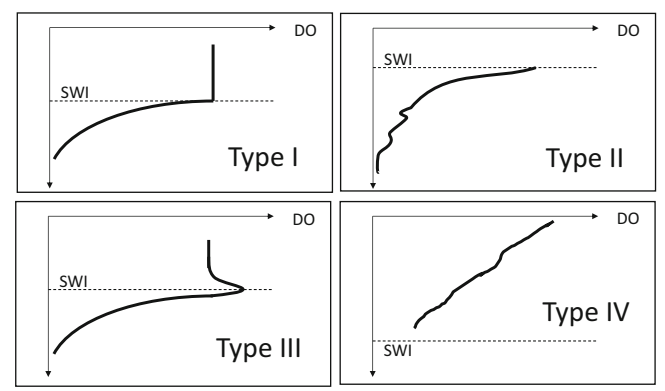

Fig. 4 Classification of DO microprofiles in the Fuyang River the overlying water in the type IV profile is attributed to the accumulation of redox substances such as Fe(II), Mn(II), S(II), methane, and ammonia (Beutel 2001, 2003; Livingstone and Imboden 1996), which originate from anaerobic diagenesis of organic matter (Froelich et al. 1979). In summary, type I profiles indicated the absence of benthic organisms and thus the degradation of the sediment habitat. Types II and III profiles indicated the activity of benthic animal and epipelic algae, which is common in the healthy aquatic sediment. Type IV profiles indicated that the excessive accumulation of pollutants in the sediment and thus the serious sediment pollution.

The oxygen profiles of the Fuyang River differed from those of unpolluted sediments. In the Fuyang River, nine sediments $(2,3,4,8,17,20,21,23,24)$ displayed type I, and nine $(1,6,7,9,10,14,15,19,22)$ displayed type III DO microprofiles. Only three sediments $(11,12,13)$ showed type II DO microprofiles, while the remaining samples $(5,16,18)$ showed type IV DO microprofiles (Fig. 5). Although the type III profile is most common in aquatic systems (Poulíčková et al. 2008), type I was dominant in the Fuyang River. The type IV profile is scarce in unpolluted sediment (Berg et al. 1998), but was observed three times in the present study.

The type III DO microprofile indicated the existence of epipelic algae. The sediment was incubated in the dark, and profile measurement was made in illuminated room. The sediment was illuminated before the preparatory work of oxygen profile measurement was completed, and the illumination time was more than $2 \mathrm{~min}$. This time should be enough to stimulate the microalgae because in the study of Revsbech and Jorgensen (1983), the light-dark cycle was only several seconds, and the oxygen concentration in the sediment surface showed obvious increase from dark to light. Therefore, the microalgae in our sediment surface should also be able to launch photosynthesis and increase the oxygen content of the SWI. Besides, a light green film was observed in most of the sediment with type III oxygen profile, which proved the existence of the epipelic algae indirectly.

It is expected that epipelic algae, which is widespread in shallow freshwater ecosystems (Poulíčková et al. 2008), would be common in the Fuyang River, where most tributaries are typical shallow freshwater ecosystems. However, the type I DO microprofile was dominant in the Fuyang River, indicating the absence of epipelic algae. The type II DO microprofile is characterized by benthic fauna activity and reflects a healthy benthic condition. However, only two sediment samples collected from the Fuyang River showed a type II DO microprofile. The appearance of a type IV profile indicated that anaerobic diagenesis may be common in the Fuyang River. However, this phenomenon is rare in sediments of clean water system. In summary, the distribution of oxygen microprofile type indicated that the sediment oxygen consumption process in the Fuyang River was strongly influenced by the deteriorated benthic condition. 
Fig. 5 Spatial distribution of oxygen profile type in the Fuyang River

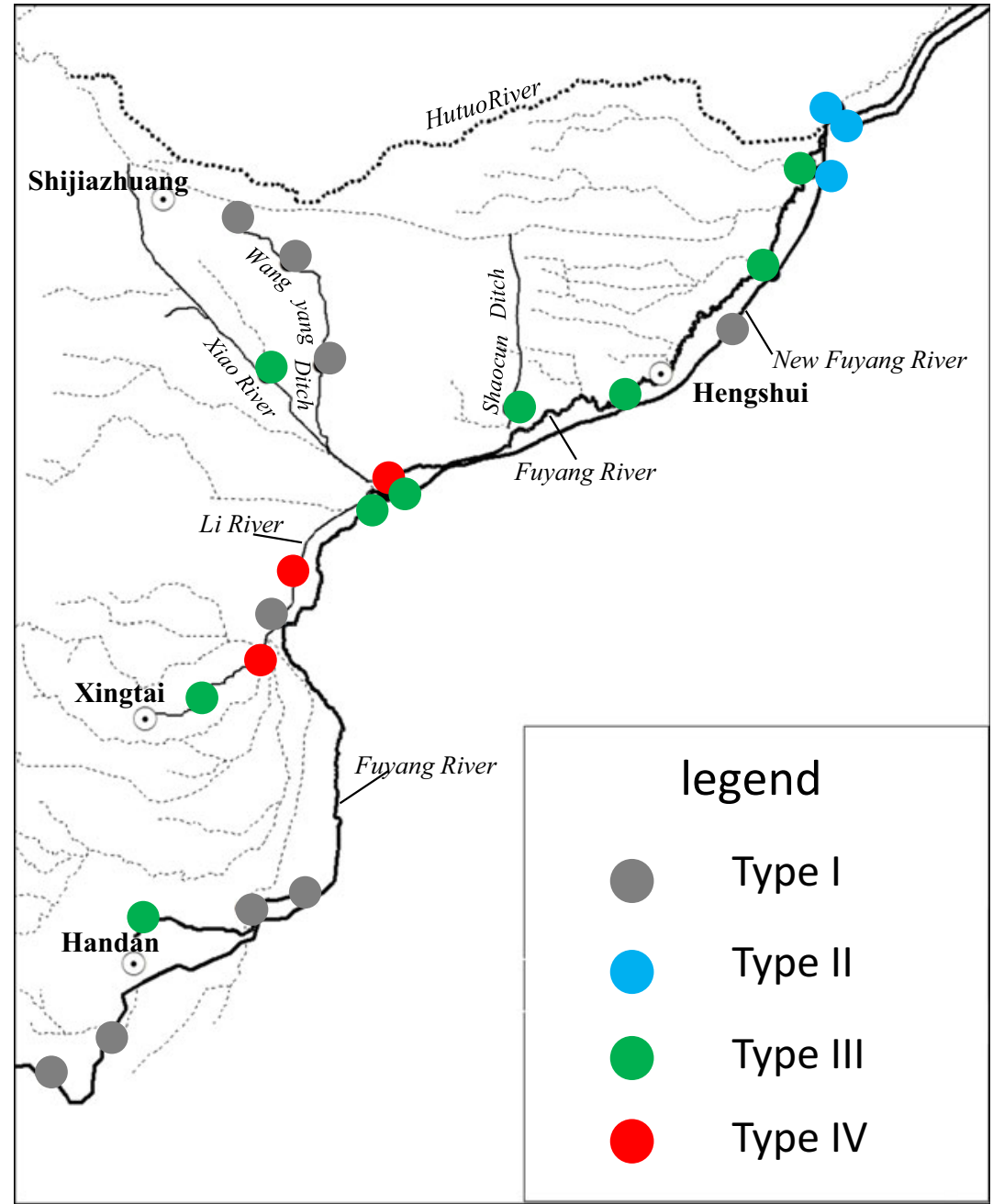

The deterioration of sediment and occurrence of type I and type IV oxygen microprofiles in the Fuyang River were closely related to the development of high-polluting industries. Type I oxygen profile is mainly distributed in the Handan Reach and Wangyang Ditch. In the Handan Reach, metallurgy is the primary source of wastewater, and in the Wangyang Ditch, pharmacy is the most important source of wastewater. The impaired benthos is always coupled to significant exposure to toxins, such as heavy metals (Ciutat et al. 2005) and antibiotics (Chelossi et al. 2003). The pharmacy industry can produce large amounts of antibiotic wastewater (Jun and Zhengyu 1997), and metallurgy wastewater contains many heavy metals. Type IV oxygen profile is mainly distributed in the Li River. Most of wastewater in the Li River comes from papermaking industry, and the concentration of organic matter is very high in papermaking wastewater. Too many oxygen-consuming substances have accumulated in the sediment, and they are now easily released to the overlying water. The anaerobic diagenesis of these substances also produces large amount of reduced substances and released to the overlying water. Both of the organic matter and the reduced substances may contribute to the appearance of type IV oxygen profile.

There were three sediments $(5,16,18)$ showing type IV oxygen profile, and their organic content were all high (24.76, 16.52 , and $13.50 \%)$. Some sediments with type III oxygen profile also had very high organic matter, such as sediment 6 (14.70\%), sediment $14(23.64 \%)$, and sediment 15 $(29.13 \%)$. However, the high organic matter in these sediments did not produce intensive oxygen consumption in the overlying water, which may be attributed to the composition of the sediment. It has been mentioned that the consumption of DO in the overlying water in the type IV profile is caused by the accumulation of redox substances such as Fe(II) and $\mathrm{Mn}(\mathrm{II})$, which originate from anaerobic diagenesis of organic matter (Froelich et al. 1979). The amount of redox substances was not only dependent on the organic matter but also on the content of iron and manganese oxides. The metallic oxide in sediments 6,14 , and 15 may be insufficient to produce as much redox substances as those sediments with type IV oxygen profiles and thus showed a less extent of oxygen consumption in the overlying water. 


\section{Conclusions}

DO microprofiles in the Fuyang River could be divided into four types that reflected different oxygen consumption processes inside the sediment. The dominance of type I profiles indicated that the benthic organisms were not involved in the oxygen consuming processes in most area of the Fuyang River because of the degradation of the sediment habitat. The appearance of type IV profiles in the Fuyang River indicated that the sediment oxygen consumption process in the Fuyang River was strongly influenced by the deteriorated benthic conditions. The development of high-polluting industries, especially metallurgy, pharmacy, and papermaking, may be responsible for the sediment deterioration and occurrence of type I and type IV oxygen microprofiles in the Fuyang River.

Acknowledgments This work was financially supported by the National Water Pollution Control and Management Technology Major Projects of China (nos. 2012ZX07203-006 and 2012ZX07203-003)

Compliance with ethical standards We confirm that this manuscript has not been published elsewhere and is not under consideration by another journal. All authors have approved the manuscript and agreed with submission to Environmental Science and Pollution Research.

We also confirm that no data have been fabricated or manipulated (including images) to support our conclusions, that no data, text, or theories by others are presented as if they were our own, and that authors whose names appear on the submission have contributed sufficiently to the scientific work and therefore share collective responsibility and accountability for the results.

Conflict of interest The authors declare that they have no competing interests.

\section{References}

Aller RC (1980) Quantifying solute distributions in the bioturbated zone of marine sediments by defining an average microenvironment. Geochim Cosmochim Acta 44(12):1955-1965

Aller RC, Aller JY (1998) The effect of biogenic irrigation intensity and solute exchange on diagenetic reaction rates in marine sediments. J Mar Res 56(4):905-936

Berg P, Risgaard-Petersen N, Rysgaard S (1998) Interpretation of measured concentration profiles in sediment pore water. Limnol Oceanogr 43(7):1500-1510

Berner RA (1980) Early diagenesis: a theoretical approach, vol 1. Princeton University, Princeton

Beutel MW (2001) Oxygen consumption and ammonia accumulation in the hypolimnion of Walker Lake, Nevada. Hydrobiologia 466(1-3): $107-117$

Beutel MW (2003) Hypolimnetic anoxia and sediment oxygen demand in California drinking water reservoirs. Lake Reserv Manage 19(3): 208-221

Blackburn TH, Blackburn ND, Jensen K, Risgaard-Petersen N (1994) Simulation model of the coupling between nitrification and denitrification in a freshwater sediment. Appl Environ Microbiol 60(9): 3089-3095
Brendel PJ, Luther GWIII (1995) Development of a gold amalgam voltammetric microelectrode for the determination of dissolved $\mathrm{Fe}$, $\mathrm{Mn}, \mathrm{O}_{2}$, and $\mathrm{S}(-\mathrm{II})$ in porewaters of marine and freshwater sediments. Environ Sci Technol 29(3):751-761

Cai W-J, Sayles FL (1996) Oxygen penetration depths and fluxes in marine sediments. Mar Chem 52(2):123-131

Cai WJ, Luther GW, Cornwell JC, Giblin AE (2010) Carbon cycling and the coupling between proton and electron transfer reactions in aquatic sediments in lake Champlain. Aquat Geochem 16(3):421-446

Chelossi E, Vezzulli L, Milano A, Branzoni M, Fabiano M, Riccardi G, Banat IM (2003) Antibiotic resistance of benthic bacteria in fishfarm and control sediments of the Western Mediterranean. Aquaculture 219(1):83-97

Ciutat A, Gerino M, Mesmer-Dudons N, Anschutz P, Boudou A (2005) Cadmium bioaccumulation in Tubificidae from the overlying water source and effects on bioturbation. Ecotoxicol Environ Saf 60(3): 237-246

Danise S, Twitchett RJ, Little CT, Clémence M-E (2013) The impact of global warming and anoxia on marine benthic community dynamics: an example from the Toarcian (Early Jurassic). PLoS One 8(2): e56255

Di Toro DM, Connolly JP (1980) Mathematical models of water quality in large lakes part 2: Lake Erie

Dufour SC, Desrosiers G, Long B, Lajeunesse P, Gagnoud M, Labrie J, Archambault P, Stora G (2005) A new method for three-dimensional visualisation and quantification of biogenic structures in aquatic sediments using axial tomodensitometry. Limnol Oceanogr Methods 3:372-380

Ferguson N, White CR, Marshall DJ (2013) Competition in benthic marine invertebrates: the unrecognized role of exploitative competition for oxygen. Ecology 94(1):126-135

Froelich PN, Klinkhammer GP, Bender ML, Luedtke NA, Heath GR, Cullen D, Dauphin P, Hammond D, Hartman B, Maynard V (1979) Early oxidation of organic matter in pelagic sediments of the eastern equatorial Atlantic: suboxic diagenesis. Geochim Cosmochim Acta 43(7):1075-1090

Gunnison D, Chen RL, Brannon JM (1983) Relationship of materials in flooded soils and sediments to the water quality of reservoirs-I: Oxygen consumption rates. Water Res 17(11):1609-1617

Hanes N, Irvine RL (1966) Oxygen uptake rates of benthal systems by a new technique. Proceedings of the 21st Industrial Waste Conference

Hargrave BT (1969) Epibenthic algal production and community respiration in the sediments of Marion Lake. J Fisheries Board Canada 26(8):2003-2026

Jun Y, Zhengyu L (1997) Advances in biological treatment processes of antibiotic production wastewater (in Chinese). Chin J Environ Sci 3: $1-6$

Komada T, Reimers GE et al (1998) Dissolved inorganic carbon profiles and fluxes determined using $\mathrm{pH}$ and microelectrodes. Limnol Oceanogr 43(5):769-781

Kristensen E (1983) Ventilation and oxygen uptake by three species of Nereis (Annelida: Polychaeta). I Effects of hypoxia Mar Ecol-Prog Ser 12(3):289-297

Li HM, Huo JM, Yu H (2000) Comprehensive assessment of water pollution and water quality for the Haihe River Basin (in Chinese). Water Resources Protect 4:1-4

Liu L, Li F, Xiong D, Song C (2006) Heavy metal contamination and their distribution in different size fractions of the surficial sediment of Haihe River, China. Environ Geol 50(3):431-438

Livingstone DM, Imboden DM (1996) The prediction of hypolimnetic oxygen profiles: A plea for a deductive approach. Can J Fish Aquat Sci 53(4):924-932

Luther GW III, Glazer BT, Ma S, Trouwborst RE, Moore TS, Metzger E, Kraiya C, Waite TJ, Druschel G, Sundby B (2008) Use of voltammetric solid-state (micro) electrodes for studying biogeochemical processes: laboratory measurements to real time 
measurements with an in situ electrochemical analyzer (ISEA). Mar Chem 108(3-4):221-235

Matlock MD, Kasprzak KR, Osborn GS (2003) Sediment oxygen demand in the Arroyo Colorado river. J Am Water Resour Assoc 39(2):267-275

Mehring AS, Kuehn KA, Tant CJ, Pringle CM, Lowrance RR, Vellidis G (2014) Contribution of surface leaf-litter breakdown and forest composition to benthic oxygen demand and ecosystem respiration in a South Georgia blackwater river. Freshwater Sci 33(2):377-389

Pischedda L, Poggiale J-C, Cuny P, Gilbert F (2008) Imaging oxygen distribution in marine sediments. The importance of bioturbation and sediment heterogeneity. Acta Biotheor 56(1-2):123-135

Poulíčková A, Hašler P, Lysáková M, Spears B (2008) The ecology of freshwater epipelic algae: an update. Phycologia 47(5):437-450

Revsbech NP, Jorgensen BB (1983) Photosynthesis of benthic microflora measured with high spatial resolution by the oxygen microprofile method: capabilities and limitations of the method. Limnol Oceanogr 28(4):749-756
Sun S, Huang S, Sun X, Wen W (2009) Phosphorus fractions and its release in the sediments of Haihe River, China. J Environ Sci(China) 21(3):291-295

Sweerts JPRA, Bar-Gilissen MJ, Cornelese AA, Cappenberg TE (1991) Oxygen-consuming processes at the profundal and littoral sedimentwater interface of a small meso-eutrophic lake (Lake Vechten, The Netherlands). Limnol Oceanogr 36(6):1124-1133

Van Cappellen P, Wang Y (1996) Cycling of iron and manganese in surface sediments: a general theory for the coupled transport and reaction of carbon, oxygen, nitrogen, sulfur, iron, and manganese. Am J Sci 296(3): 197-243

WRPBHRB (Water Resource Protection Bureau of Haihe River Basin) (2013) Haihe river basin water resource bulletin

Wei-min Y (2009) Research progress in techniques of tannery wastewater treatment $[\mathrm{J}]$. Leather Chem 2:004

Wenzan L, Xuyong L, Huiliang W, Jingjun S (2012) Spatial distribution of the main contaminations in aquatic environment in Fuyang River (in Chinese). Acta Sci Circumst 32(11):2814-2819

Wetzel RG (2001) Limnology: lake and river ecosystems. Academic Press 